\title{
The effects of age, dietary restriction, exercise and maternity on the abundance and volume of adipocytes in twelve adipose depots of adult guinea-pigs
}

\author{
BY CAROLINE M. POND, CHRISTINE A. MATTACKS, \\ MARION C. THOMPSON AND DAWN SADLER \\ Department of Biology, The Open University, Milton Keynes MK7 6AA
}

(Received 13 September 1985 - Accepted 22 January 1986)

\begin{abstract}
1. The mean adipocyte volume and cellularity of adipose tissue in twelve anatomically defined depots were measured in 190 virgin and reproductive guinea-pigs aged 6 months to 2 years, maintained on five different regimens of diet and exercise.

2. The total adipocyte complement was constant up to the age of about 10 months and increased by $65-70 \%$ during the 2 nd year of life. At constant percentage body-weight as fat, age-related accumulation of adipocytes was accompanied by reduction in average adipocyte volume. A period of high percentage body-weight as fat was not a necessary antecedent to age-related accumulation of adipocytes, and the effect was not observed in specimens that exercised regularly.

3. In guinea-pigs over 13 months old, changes in adipose tissue cellularity made a major contribution to total fatness. The mean volume of samples of adipocytes was a satisfactory indicator of fatness only in younger specimens in which adipose tissue cellularity was not changing.

4. The lean body mass and the total adipocyte complement were lower in guinea-pigs on the sedentary, restricted-diet regimen, whether the regimen began at the age of 19 weeks or 31 weeks, but the depots studied were not equally affected. Both moderate and strenuous exercise on an ad lib. diet caused a reduction in the percentage body-weight as fat in males but not in females. The total adipocyte complement and lean body mass were unchanged, although the males became almost as thin following exercise as those on the restricted-diet regimen.
\end{abstract}

5. Among guinea-pigs under $400 \mathrm{~d}$ old, there were no significant differences between males and virgin females in the site-specific volume of adipocytes relative to the size of those in other depots of the same specimen; there was only one significant difference in this index between the older and the younger specimens. The diet and exercise regimens modified the site-specific adipocyte volume relative to those in other depots; adipocytes under the trapezius muscle of the neck (UMN), at the interscapular depot (HUMP) and those in the depots anterior to the forelimb became relatively smaller following exercise, while those in the popliteal fat mass were relatively larger. Adipocytes in the UMN and HUMP also became more numerous relative to those in the other depots following both moderate and strenuous exercise. Those in the groin site, the intra-abdominal depots and the intermuscular depots became relatively smaller following dietary restriction without exercise.

6. The retroperitoneal depot was the most consistently and extensively depleted following dietary restriction without exercise, and the mesenteric and omental, ventral groin and anterior forelimb depots were not significantly depleted in any of the virgin guinea-pigs on this regimen. Thus those on the restricted diet had more adipocytes at these depots, in proportion to lean body mass, than the ad lib.-fed controls. Following age-related adipocyte proliferation, there were relatively more adipocytes in the abdominal depots, and relatively fewer in depots around the forelimbs in guinea-pigs that were first exercised strenuously and then placed on a sedentary at lib.-feeding regimen, compared with never-exercised controls.

7. Some of the correlation coefficients between the volumes of adipocytes in all depots studied were significantly higher in the ad lib.-fed, sedentary mothers than in ad lib.-fed sedentary males of the same age. No other effects of maternity on site-specific differences in the relative volume or relative abundance of adipocytes were identified.

8. Site-specific differences in adipocyte accumulation contributed more to age and regimen-related changes in body conformation than changes in the relative volume of adipocytes.

Information from both laboratory rodent studies (Cryer \& Jones, 1978; Fried et al. 1982; Pond et al. 1984a, b) and humans (Björntorp et al. 1975) has shown that adipose tissue from different depots of the same individual differs both anatomically and biochemically. Furthermore, anatomically homologous depots have similar cellular structure in a wide range of eutherian and marsupial mammals (Pond \& Mattacks, 1985a; Pond, 1986); the 
relative volume of adipocytes is qualitatively similar in homologous depots, but the relative abundance of adipocytes at each depot varies greatly between species and between specimens. Almost nothing is known about the causes and physiological correlates of naturally occurring differences in the anatomical distribution of adipose tissue (Pond, 1986), in spite of the relevance of such knowledge to the manipulation of human figure shapes and carcass conformation of meat animals. There have been many studies of site-specific differences in the growth and biochemical properties of distinct adipose depots (Björntorp et al. 1975; Cryer \& Jones 1978; Faust et al. 1978; Fried et al. 1982), but a complete picture of the effects of age and regimen on body conformation involves following the growth of adipose tissue in all major depots simultaneously. In the present paper we have investigated the response of adipose tissue in twelve distinct depots to various regimens of diet and exercise, in the hope of identifying site-specific factors that may underlie interspecific and inter-individual differences in body conformation.

The cellularity of the adipose tissue at certain intra-abdominal and inguinal depots of laboratory rats is significantly greater in specimens over 1 year old than in young adults (Lemmonier, 1972; Stiles et al. 1975), but it is not clear whether this effect is centrally controlled and occurs in all adipose depots, or whether it is necessarily caused by an increase in overall fatness. There was much inter-individual variation in the total adipocyte complement that could not be related to differences in fatness in the 202 randomly collected wild, laboratory and domestic mammals studied by Pond \& Mattacks (1985 b). The age of most of these specimens was unknown, and age-related differences in total adipocyte complement may have caused the variation. We undertook the present study of the effects of age, exercise and dietary regimen on the adipose depots that had established homologies in other mammalian species, in order to identify site-specific differences in growth that may be relevant to explanations for the comparative anatomy of adipose tissue in wild and domestic mammals and humans.

\section{MATERIALS AND METHODS}

The animal husbandry, dissection and adipocyte volume determination methods used were similar to those of Pond et al. $(1984 a)$. The age, breed and body composition of the seventeen experimental groups studied are listed in Table 1.

\section{Diet and exercise regimens}

All specimens were bred and raised by the authors; breeding pairs were kept together continuously and were fed ad lib. on breeding-grade guinea-pig chow ( $33 \mathrm{~g}$ crude oil $/ \mathrm{kg}$, $9205 \mathrm{~kJ}$ metabolizable energy $/ \mathrm{kg}$ ) throughout pregnancy and lactation. The young remained with the parents until the age of 3 weeks when they were transferred to standard guinea-pig cages of area $0.5 \mathrm{~m}^{2}$ in single-sex groups of similar age, with a maximum of four males or five females per group. They were fed ad lib. on the breeding-grade chow until the special regimens were started at the age of at least $90 \mathrm{~d}$. The sedentary, ad lib.-fed group had unrestricted access to breeding-grade guinea-pig chow. The sedentary, restricted-diet groups (groups 6-10) were maintained in the same cages as the sedentary virgins and fed on the same chow for only $3 \mathrm{~h} / \mathrm{d}$ until they had lost at least $10 \%$ of their body-weight. The restricted-diet regimen started at the age (d) of 132 (SD 19) for group 6, 134 (SD 22) for group 7, 216 (SD 15) for group 8 and 222 (SD 11) for group 9. The regimen continued for (d) 71 (SD 12) for group 6, 78 (SD 6) for group 7, 52 (SD 15) for group 8 and 62 (SD 9) for group 9. Males and older animals lost weight faster than younger individuals and females. Signs of distress such as hair loss, fighting and excessive squeaking occurred in very thin animals (less than $5 \%$ body-weight as fat); all restricted-diet specimens (including several of the 
Table 1. Age, breed and body composition of the seventeen groups of guinea-pigs

(Mean values and standard deviations)

\begin{tabular}{|c|c|c|c|c|c|c|c|c|c|c|c|}
\hline \multirow{2}{*}{$\begin{array}{l}\text { Group } \\
\text { no. }\end{array}$} & \multirow[b]{2}{*}{ Age (d) } & \multirow{2}{*}{$\begin{array}{l}\text { No. in } \\
\text { group }\end{array}$} & \multirow{2}{*}{\multicolumn{3}{|c|}{$\begin{array}{l}\text { Breed composition } \\
\text { of group }\end{array}$}} & \multicolumn{2}{|c|}{$\begin{array}{l}\text { Age } \\
\text { (d) }\end{array}$} & \multicolumn{2}{|c|}{$\begin{array}{l}\text { Lean body } \\
\text { mass (g) }\end{array}$} & \multicolumn{2}{|c|}{$\begin{array}{c}\text { Percentage } \\
\text { body-wt } \\
\text { as fat }\end{array}$} \\
\hline & & & & & & Mean & SD & Mean & SD & Mean & SD \\
\hline \multicolumn{12}{|c|}{ Sedentary, ad lib.-fed } \\
\hline 1 & $150-250$ & $9 \mathrm{M}$ & $4 \mathrm{DH}$ & $2 \mathrm{Bol}$, & 3 Abys & 207 & 31 & 918 & 48 & $14 \cdot 0$ & 1.9 \\
\hline 2 & $150-250$ & $10 \mathrm{VF}$ & $6 \mathrm{DH}$ & $2 \mathrm{Bol}$ & 2 Abys & 225 & 20 & 757 & 80 & $14 \cdot 8$ & 2.8 \\
\hline 3 & $250-400$ & $13 \mathrm{M}$ & $7 \mathrm{DH}$ & 3 Bol, & 3 Abys & 314 & 32 & 943 & 117 & $11 \cdot 3$ & $2 \cdot 4$ \\
\hline 4 & over 500 & $9 \mathrm{M}$ & $3 \mathrm{DH}$, & 5 Bol, & 1 Abys & 573 & 46 & 910 & 95 & $14 \cdot 5$ & $3 \cdot 0$ \\
\hline 5 & over 300 & $11 \mathrm{RF}$ & $7 \mathrm{DH}$ & $4 \mathrm{Bol}$ & 0 Abys & 529 & 158 & 851 & 96 & $15 \cdot 1$ & $2 \cdot 2$ \\
\hline \multicolumn{12}{|c|}{ Sedentary, restricted diet } \\
\hline 6 & $150-250$ & $9 \mathrm{M}$ & $3 \mathrm{DH}$ & $6 \mathrm{Bol}$, & 0 Abys & 204 & 28 & 704 & 67 & $6 \cdot 8$ & $2 \cdot 1$ \\
\hline 7 & $150-250$ & $12 \mathrm{VF}$ & $11 \mathrm{DH}$ & $1 \mathrm{Bol}$, & 0 Abys & 212 & 21 & 649 & 73 & 6.2 & 1.7 \\
\hline 8 & $250-400$ & $9 \mathrm{M}$ & $3 \mathrm{DH}$ & $4 \mathrm{Bol}$, & 2 Abys & 268 & 15 & 735 & 82 & $5 \cdot 5$ & $2 \cdot 7$ \\
\hline 9 & $250-400$ & $8 \mathrm{VF}$ & $5 \mathrm{DH}$ & 3 Bol, & 0 Abys & 284 & 11 & 684 & 46 & $7 \cdot 5$ & $2 \cdot 4$ \\
\hline 10 & over 300 & $14 \mathrm{RF}$ & $8 \mathrm{DH}$, & 5 Bol, & 1 Abys & 554 & 176 & 793 & 101 & $7 \cdot 6$ & $3 \cdot 2$ \\
\hline \multicolumn{12}{|c|}{ Moderately exercised, ad lib.-fed } \\
\hline 11 & $200-400$ & $16 \mathrm{M}$ & $9 \mathrm{DH}$ & $3 \mathrm{Bol}$ & 4 Abys & 273 & 44 & 921 & 99 & $8 \cdot 1$ & $2 \cdot 8$ \\
\hline 12 & $200-400$ & $17 \mathrm{VF}$ & $7 \mathrm{DH}$, & $6 \mathrm{Bol}$ & 4 Abys & 301 & 53 & 724 & 66 & $13 \cdot 5$ & $2 \cdot 0$ \\
\hline \multicolumn{12}{|c|}{ Strenuously exercised, ad lib.-fed } \\
\hline 13 & $200-350$ & $15 \mathrm{M}$ & $11 \mathrm{DH}$ & $4 \mathrm{Bol}$ & 0 Abys & 290 & 45 & 890 & 82 & $8 \cdot 1$ & $2 \cdot 0$ \\
\hline 14 & $200-350$ & $10 \mathrm{VF}$ & $7 \mathrm{DH}$ & 3 Bol, & 0 Abys & 290 & 43 & 769 & 59 & $13 \cdot 0$ & $2 \cdot 6$ \\
\hline 15 & $350-550$ & $9 \mathrm{VF}$ & $5 \mathrm{DH}$ & $4 \mathrm{Bol}$, & 0 Abys & 461 & 82 & 784 & 41 & $11 \cdot 2$ & $2 \cdot 5$ \\
\hline \multicolumn{12}{|c|}{ Restricted exercise } \\
\hline 16 & under 400 & $4 \mathrm{M}, 5 \mathrm{VF}$ & $8 \mathrm{DH}$ & $1 \mathrm{Bol}$ & 0 Abys & 343 & 49 & 908 & 98 & $10 \cdot 6$ & 1.9 \\
\hline 17 & over 400 & $6 \mathrm{M}, 4 \mathrm{VF}$ & $6 \mathrm{DH}$, & $4 \mathrm{Bol}$, & 0 Abys & 489 & 78 & 884 & 109 & $11 \cdot 5$ & $1 \cdot 4$ \\
\hline
\end{tabular}

M, males; VF, virgin females; RF, mothers; DH, Dunkin Hartley; Bol, Bolivian; Abys, Abyssinian.

males in group 8) were killed as soon as these symptoms appeared. Vitamin $C(0 \cdot 1 \mathrm{mg} / \mathrm{ml})$ was added to the drinking water of all specimens, and all groups received carrots, cabbage and other fresh vegetables on $5 \mathrm{~d}$ per week.

All the males in group 4 and half of those in group 3 were fathers and were housed with one reproducing female from the age of 4 months. These males and the mothers (groups 5 and 10) were kept in cages of area $0.2 \mathrm{~m}^{2}$. The other males and virgin females (groups 1-3 and 6-9) were kept in single-sex groups of four to five animals in standard guinea-pig cages (area $0.5 \mathrm{~m}^{2}$ ) throughout their lives. The males in group 4 were approximately 1 year (mean $374 \mathrm{~d}$ ) older than those in group 1.

The exercised guinea-pigs were transferred in single-sex groups of five to eight animals to outdoor pens consisting of an enclosed gravel-covered run of area $6 \mathrm{~m}^{2}$ and a hutch of area $1.5 \mathrm{~m}^{2}$. The food and water were placed at opposite ends of the pens, $3.75 \mathrm{~m}$ apart; all these outdoor guinea-pigs were fed $a d$ lib. on the same diet as the $a d$ lib.-fed sedentary groups. They were put outside during a spell of warm, dry weather between 25 May and 9 June in 1982-5 and kept there continuously until killed for analysis from mid-September until 13 November. They were observed to exercise spontaneously, particularly in the early morning and late afternoon, and walked the $3.75 \mathrm{~m}$ between the food and the water several times each day. The moderately exercised animals (groups 11 and 12) were placed on this regimen at a mean age (d) of 161 (SD 43) for group 11, and 175 (SD 69) for group 12, and 
were not subjected to additional exercise. Their mean time-period (d) in the outdoor pen was 112 (SD 31) for the males (group 11) and 125 (SD 18) for the females (group 12).

The strenuously exercised groups (groups 13-15) were put outside at the same time and housed and fed in exactly the same way as the moderately exercised groups, but in addition to the moderate exercise regimen, they were forced to gallop about $150 \mathrm{~m}$ early each morning for $5 \mathrm{~d}$ per week. The forced exercise was started 1 month after the animals were put in the outdoor pen and continued until the day before they were killed, after an average of (d) 81 (SD 15) for group 13, 91 (SD 13) for group 14 and 96 (SD 16) for group 15 on the strenuous exercise regimen. The total period outside was similar to that of the moderately exercised animals (mean (d): 112 (SD 20) for group 13, 120 (SD 12) for group 14, 125 (SD 16) for group 15).

The females adapted very well to these regimens, losing less than $15 \%$ of their body mass during the first fortnight and regaining their original weight within 1 month. However, each year several males died or had to be removed during the first 2 weeks because of fighting between males. All indications of fighting or other sources of stress disappeared after 1 month in the outdoor pens. The Abyssinian strain was found to be much less hardy on the exercise and restricted-diet regimens, and non was placed on the exercise regimens after 1982.

The 'formerly exercised' animals (groups 16 and 17) were put in the same outdoor pens at the same time as the other exercised specimens and were subjected to the strenuous exercise regimen for the same length of time (mean $90 \mathrm{~d}$ ) as groups 13 and 14. Then all forced exercise ended and the pen was rearranged so that the water was placed beside the hutch, only $0.5 \mathrm{~m}$ away from the food. The total area available for movement was reduced to $2 \mathrm{~m}^{2}$, and galloping was impossible. The animals remained on an $a d$ lib. diet under these conditions until they were killed after about 40 (SD 7) $\mathrm{d}$ in the case of group 16 and 44 (SD 12) $\mathrm{d}$ in the case of group 17.

The mothers were mated at the age of about 14 weeks, and remained with the males throughout pregnancy, birth and lactation. The young were removed at 3 weeks of age. The mean number of weaned offspring per mother was 11 (SD 6.6) and each mother had successfully raised at least four young. The 'sedentary unrestricted' mothers (group 5) were removed from the males before giving birth to their final litter and maintained on an ad lib. diet for at least 2 months after the young were weaned. The 'restricted-diet' mothers (group no. 10) were also removed from the male before the final birth and were prevented from gaining weight when lactation ended by placing them on the restricted-diet regimen for a mean of $21 \mathrm{~d}$ as soon as the young were weaned.

The restricted-diet and outdoor guinea-pigs were weighed every fortnight and on the day they were killed, and the sedentary specimens on the day they were killed, by an overdose of urethane $(6-10 \mathrm{ml}$ of a $500 \mathrm{mg} / \mathrm{ml}$ solution injected intraperitoneally (i.p.)) or pentabarbitone $(2-4 \mathrm{ml}$ of a $30 \mathrm{mg} / \mathrm{ml}$ solution, injected i.p.). The lean body mass was calculated as the difference between the live body mass and the total mass of adipose tissue.

\section{Determination of adipocyte volume and adipose tissue cellularity}

The intact body was stored at $4-8^{\circ}$ for $2-24 \mathrm{~h}$ and completely dissected. The definition and anatomical relations of the twelve adipose depots studied were described in detail by Pond et al. $(1984 a, b)$ : adipose tissue anterior to deltoideus and lateral to trapezius and omotransversarius muscles (IFS); tissue on the anterior and lateral surfaces of the forelimb, anterior to the biceps brachii muscle (IFA); tissue posterior to the humerus and in the axilla, extending posteriorly over the chest muscles (BA); tissue medial to the trapezius and cleidobrachialis muscles (UMN); superficial, medial adipose tissue between the dorsal crests of the scapulas (HUMP); superficial, medial adipose tissue in the groove between the lower jaws (DC); adipose tissue anterior to the femur from hip to knee, lateral to the abdominal 
wall and medial to the panniculus muscle (GS); medial ventral adipose tissue on the outside of the abdominal wall between the hind-limbs $(\mathrm{GV})$; perirenal, gonadal and retroperitoneal adipose tissue (DWA); omental and mesenteric adipose tissue (ATG); popliteal fat mass (POP); adipose tissue medial to the gluteus superficialis muscle (GL). All these depots consist of typical storage adipose tissue that expands or shrinks in response to nutritional conditions and together they account for more than $95 \%$ of all dissectable adipose tissue in the body (Pond et al. 1984a, $b$; Mattacks \& Pond, 1985).

The diameters of about forty adipocytes were measured from unfixed, unstained whole mounts of samples taken from the middle of each depot and the average adipocyte volume was calculated from the mean and standard deviation of these measurements using the formula of Goldrick (1967). All adipocyte volume determinations were performed by the same two authors (CAM and MCT), whose measurements were cross-checked to ensure that there was no significant difference between values obtained by the two observers.

The samples were examined in a random order and, in the case of four depots (in front of arm (IFA), in front of shoulder (IFS), under neck muscles (UMN) and behind arm (BA)), homologous samples from the left and the right sides of the body were measured separately. The numbers of adipocytes at each depot were calculated from its gross mass and the site-specific mean adipocyte volume, assuming that the density of guinea-pig adipose tissue is 0.873 (Di Girolamo et al. 1971). For the two intermuscular depots in the hind-leg, the number of adipocytes for the whole depot was calculated from the mean volume of adipocytes at sample GL1, and from the average of POP8 and POP9 for POP (Pond et al. $1984 \mathrm{~b}$ ). The sum of the number of adipocytes at each depot yields the total adipocyte complement. The index MEANCS (mean cell volume), arbitrarily defined by Pond et al. $(1984 a)$ as the arithmetic mean of the volume of adipocytes from all the body sites studied, including the values from the four left-right homologous pairs of sites, was calculated to provide a measure of the average adipocyte volume in each specimen. Thus defined, the index MEANCS does not take account of the relative mass of the depots studied.

Conventional computing systems and Statistical Package for the Social Sciences (Nie et al. 1975) were used to analyse the data.

\section{RESULTS}

Body composition and total adipocyte complement

Age effects. The values in Tables 1 and 2 show that on the sedentary, ad lib.-fed regimen, there was no change with age in the lean body masses of the males (groups 1, 3 and 4) and only a small difference in lean body mass between the older mothers (group 5) and the younger virgin females (group 2) (Student's $t$ test, $t 2 \cdot 45, P<0.05$ ). Thus there was very little growth of the lean tissues during the period of the life-history investigated. The lean body masses of the sedentary, ad lib.-fed virgin females (group 2) were significantly smaller than those of the males of the same age (group 1) (Student's $t$ test, $t 5 \cdot 38, P<0.01$ ) but the difference between the oldest males (group 4) and the mothers (group 5) was not significant.

Among the sedentary, ad lib.-fed males, the percentage body-weight as fat was slightly, though significantly, lower in the group 3 animals than in groups 1 or 4 (Student's $t$ test, $t 2.66$ and 2.94, $P<0.05$ ). However, the greater leanness of group 3 compared with group 1 was due entirely to smaller mean adipocyte volume (MEANCS); the mean values for lean body mass, total adipocyte complement and the number of adipocytes per $\mathrm{kg}$ body mass of group 3 were similar to those of the slightly younger males (group 1). As there was quite substantial variation in fatness between specimens on the same regimen, we believe that this small difference between groups 1 and 3 was due to random sampling and has no 
Table 2. Total adipocyte complement, number of adipocytes per $\mathrm{kg}$ lean body mass and mean adipocyte volume (MEANCS) in guinea-pigs maintained on different regimens of diet and exercise

(Mean values and standard deviations)

\begin{tabular}{|c|c|c|c|c|c|c|c|c|}
\hline \multirow{2}{*}{$\begin{array}{c}\text { Group } \\
\text { no.* }\end{array}$} & \multicolumn{2}{|c|}{$\begin{array}{l}\text { No. of } \\
\text { adipocytes } \\
\left(\times 10^{6}\right)\end{array}$} & \multicolumn{2}{|c|}{$\begin{array}{l}\text { No. }\left(\times 10^{6}\right) \\
\text { of adipocytes } \\
\text { per kg lean } \\
\text { body mass }\end{array}$} & \multicolumn{2}{|c|}{$\begin{array}{l}\text { MEAŇCS } \\
(\mathbf{n 1})\end{array}$} & \multicolumn{2}{|c|}{$\begin{array}{l}\text { Percentage of } \\
\text { body-wt lost } \\
\text { during regimen }\end{array}$} \\
\hline & Mean & SD & Mean & SD & Mean & SD & Mean & SD \\
\hline \multicolumn{9}{|c|}{ Sedentary, ad lib.-fed } \\
\hline 1 & $107 \cdot 4$ & $15 \cdot 6$ & $117 \cdot 1$ & $16 \cdot 6$ & 1.540 & $0 \cdot 271$ & & \\
\hline 2 & $87 \cdot 2$ & $14 \cdot 0$ & $115 \cdot 9$ & $19 \cdot 7$ & 1.620 & $0 \cdot 301$ & & \\
\hline 3 & $109 \cdot 4$ & $33 \cdot 3$ & $115 \cdot 2$ & $28 \cdot 0$ & $1 \cdot 319$ & 0.400 & & \\
\hline 4 & $179 \cdot 3$ & $78 \cdot 8$ & $193 \cdot 6$ & $76 \cdot 2$ & $1 \cdot 045$ & $0 \cdot 305$ & & \\
\hline 5 & $168 \cdot 9$ & $57 \cdot 9$ & $196 \cdot 4$ & $52 \cdot 7$ & 1.046 & 0.323 & & \\
\hline \multicolumn{9}{|c|}{ Sedentary, restricted diet } \\
\hline 6 & $70 \cdot 7$ & $28 \cdot 0$ & $99 \cdot 6$ & $38 \cdot 1$ & 0.883 & $0 \cdot 281$ & 14.8 & $5 \cdot 1$ \\
\hline 7 & $73 \cdot 0$ & $23 \cdot 4$ & $114 \cdot 3$ & $41 \cdot 0$ & 0.828 & 0.437 & $13 \cdot 4$ & $7 \cdot 5$ \\
\hline 8 & $84 \cdot 4$ & $21 \cdot 9$ & $115 \cdot 1$ & $26 \cdot 2$ & 0.640 & 0.332 & $20 \cdot 9$ & $6 \cdot 1$ \\
\hline 9 & $75 \cdot 2$ & $14 \cdot 5$ & $110 \cdot 0$ & $20 \cdot 0$ & 0.950 & 0.337 & $12 \cdot 6$ & $6 \cdot 0$ \\
\hline 10 & $113 \cdot 8$ & $45 \cdot 5$ & $145 \cdot 1$ & $60 \cdot 2$ & $0 \cdot 702$ & 0.260 & $15 \cdot 2$ & $8 \cdot 7$ \\
\hline \multicolumn{9}{|c|}{ Exercised, ad lib.-fed } \\
\hline 11 & $101 \cdot 8$ & $28 \cdot 4$ & $121 \cdot 4$ & $38 \cdot 0$ & 0.790 & $0 \cdot 142$ & $3 \cdot 0$ & $9 \cdot 0$ \\
\hline 12 & $106 \cdot 9$ & $26 \cdot 3$ & $147 \cdot 7$ & $34 \cdot 0$ & $1 \cdot 237$ & 0.231 & $-3 \cdot 8$ & $8 \cdot 5$ \\
\hline 13 & $116 \cdot 3$ & $32 \cdot 8$ & $131 \cdot 0$ & $36 \cdot 1$ & 0.792 & $0 \cdot 151$ & $4 \cdot 0$ & $9 \cdot 0$ \\
\hline 14 & $104 \cdot 4$ & $46 \cdot 4$ & $134 \cdot 6$ & 51.4 & $1 \cdot 253$ & 0.211 & $2 \cdot 0$ & $9 \cdot 6$ \\
\hline 15 & $109 \cdot 9$ & $29 \cdot 4$ & $139 \cdot 5$ & $33 \cdot 2$ & 1.021 & $0 \cdot 186$ & 0.7 & $7 \cdot 8$ \\
\hline 16 & 117.6 & $39 \cdot 5$ & $129 \cdot 3$ & 38.7 & 1.059 & $0 \cdot 217$ & $2 \cdot 1$ & $6 \cdot 1$ \\
\hline 17 & $153 \cdot 1$ & $30 \cdot 6$ & $173 \cdot 3$ & $28 \cdot 5$ & 0.838 & 0.091 & 0.1 & $9 \cdot 0$ \\
\hline
\end{tabular}

* For details of groups, see Table 1.

biological significance. There was no difference in percentage body-weight as fat between sedentary ad lib.-fed males and females of the same age.

The numbers of adipocytes per kg body mass were similar in sedentary, ad lib.-fed males and females of the same age. This index did not change significantly in males between the ages of approximately 7 months (group 1) and 10 months (group 3), but the number of mature adipocytes per $\mathrm{kg}$ lean body mass was $65 \%$ greater in group 4 than in the group 1 males, which were approximately 1 year younger (Student's $t$ test, $t 2.94, P<0.05$ ). The number of adipocytes per $\mathrm{kg}$ lean body mass was $70 \%$ greater in the sedentary ad lib.-fed mothers aged approximately 18 months (group 5) than in the virgin females aged about 7 months (group 2) (Student's $t$ test, $t 4.67, P<0.001$ ). There was no significant difference in the MEANCS of the males in groups 1 and 3, or between young virgin males and females (groups 1 and 2), but the values for MEANCS were significantly lower in the oldest specimens of both sexes (groups 4 and 5) compared with those for the younger controls (Student's $t$ test, $t 3.64, P<0.01$ for groups 1 and 4 , and $t 4.22, P<0.001$ for groups 2 and 5), although the mean values for percentage body-weight as fat were similar in groups $1,2,4$ and 5.

Effects of dietary restriction. All specimens in groups 6-10 lost weight during the period in which the sedentary, restricted-diet regimen was imposed. The lean body mass and the percentage body-weight as fat of the younger virgin guinea-pigs (groups 6-9) were less than 
those of ad lib.-fed specimens of the same age and sex (Student's $t$ test, $t 7.79$ and 7.63 , $P<0.001$ for groups 1 and 6 respectively; $t 3.28$ and $8.50, P<0.01$ for groups 2 and 7 respectively; $t 4.90$ and $5.18, P<0.001$ for groups 3 and 8 respectively). However, the lean body masses of the restricted-diet mothers (group 10) were not significantly smaller than those of the ad lib.-fed mothers (group 5), although the former group had much less adipose tissue. The total adipocyte complement was also smaller in groups 6-9, but the number of adipocytes per $\mathrm{kg}$ body mass was similar in restricted diet animals and age-matched groups of virgin ad lib.-fed animals of the same sex (groups 1-3).

There was no significant difference between groups 6-10 in the percentage body-weight as fat, although the older males (group 9) lost more body-weight during the regimen than the age-matched virgin females (group 8) (Student's $t$ test, $t 2.83, P<0.05$ ). The number of mature adipocytes per $\mathrm{kg}$ lean body mass was variable in the restricted-diet mothers (group 10), but the mean value was not significantly different from that of the younger restricted-diet virgin females (groups 7 and 9), and there were significantly fewer adipocytes per $\mathrm{kg}$ body mass in the restricted-diet mothers (group 10) than in the ad lib.-fed mothers (group 5) of the same age (Student's $t$ test, $t 2 \cdot 27, P<0.05$ ).

Effects of exercise. The lean body masses of the five groups that were exercising regularly up to the time of death (groups 11-15) were not significantly different from those of the corresponding groups of sedentary ad lib.-fed guinea-pigs (groups 1-4). The percentage of the total body mass lost during the exercise regimen was variable, particularly in the case of the males, but none of the mean values was significantly different from zero. However, the body composition of the males was very different from that of the females on both the regimens of exercise; in both the moderately exercised and strenuously exercised groups males were significantly thinner than the females of similar age (Student's $t$ test, $t 6.34$ and $5.27, P<0.001)$. The mean values for percentage body-weight as fat of the younger exercised females (groups 12 and 14) were not significantly different from those of sedentary ad lib.-fed controls of similar age, and this index was not significantly different in the older (group 15) and the younger (group 14) strenuously exercised females. However, the strenuously exercised older virgin females (group 15) were significantly thinner than the never-exercised mothers of similar age (group 5; Student's $t$ test, $t 3.66, P<0.01$ ). The percentage body-weight as fat of the moderately exercised males (group 11) was not significantly different from that of the restricted-diet males (groups 6 and 8 combined), but that of the strenuously exercised males (group 13) was highly significantly less than for the sedentary, ad lib.-fed males of similar age (groups 1 and 3 combined; Student's $t$ test, $t 7.07$, $p<0.001$ ). The decrease in adipose tissue mass in the exercising males was due entirely to changes in adipocyte volume; there was no significant difference between the numbers of adipocytes per kg body mass of the exercised groups (groups 11 and 13) and that of the age-matched control groups, but values for MEANCS of the males were very significantly smaller than those of the sedentary, ad lib.-fed males (groups 1 and 3 combined) (Student's $t$ test, $t 9 \cdot 26, P<0 \cdot 001$ ).

The numbers of adipocytes per kg body mass were significantly greater in the moderately exercised females (group 12) than in the sedentary ad lib.-fed females (group 2; Student's $t$ test, $t 3.08, P<0.01$ ), probably because the sedentary ad lib.-fed animals in the latter group were younger than the exercising ones. However, the numbers of adipocytes per $\mathrm{kg}$ body mass of both groups of strenuously exercised females (groups 14 and 15) were not significantly different from those of the sedentary, ad lib.-fed females (group 2), although the latter were much younger. The values for MEANCS were significantly smaller (Student's $t$ test, $t 5 \cdot 27-3 \cdot 16, P<0 \cdot 01$ ) in the exercised females (groups 12,14 and 15 ) than in the sedentary females (group 2).

The mean values for lean body mass of formerly exercised groups (groups 16 and 17) 
were not significantly different from that of the strenuously exercised animals (groups 13-15) and the guinea-pigs did not become fatter after the exercise regimens had ended (mean fatness of groups 13 and 14 combined $10 \cdot 1$ (SD 3.3) \%). The numbers of adipocytes per $\mathrm{kg}$ lean body mass were not significantly greater in the younger specimens on the restrictedexercise regimen (group 16) from that of the strenuously exercised groups (groups 13 and 14 combined). However, this index was $31 \%$ greater in the ten oldest animals on the restricted-exercise regimen (group 17, mean age 16 months) than in the younger strenuously exercised animals (groups 13 and 14 combined). This difference was highly significant (Student's $t$ test, $t 3.32, P<0.001$ ), and there was a corresponding decrease in the MEANCS in this group (Student's $t$ test, $t 2 \cdot 14, P<0 \cdot 05$ ). The numbers of adipocytes per $\mathrm{kg}$ lean body mass in the older, formerly exercised specimens (group 17) were not significantly different from those of the never-exercised ad lib.-fed specimens of similar age (groups 4 and 5 combined), although the latter groups were fatter and had correspondingly larger adipocytes.

Differences between breeds. There were enough specimens of all three breeds in the sedentary, ad lib.-fed males (groups 1 and 3), and male and female exercised specimens (groups 11 and 13 and groups 12 and 14). The only significant difference between breed was that the six sedentary ad lib.-fed Abyssinians were fatter than similarly maintained specimens of the other breeds (Student's $t$ test, $t 2.93, P<0.05$ ). This difference was due entirely to an increase in MEANCS.

Relation between adipocyte volume and percentage body-weight as fat. Fig. 1 shows the relations between MEANCS and percentage body-weight as fat for the forty-eight guinea-pigs in groups $4,5,10,15$ and 17 that were older than $400 \mathrm{~d}$, and for the ninety-seven specimens aged $150-300 \mathrm{~d}$ in groups $1-3,6-9,11-14$ and 16 . The values are scattered, particularly those from the fatter specimens. In the older specimens, increased adipose tissue cellularity makes such an important contribution to fattening that MEANCS changes less than twofold for a tenfold range in fatness. The calculated regression equations are:

MEANCS $=0.089$ (percentage body-weight as fat) $+0.211, r 0.830, \mathrm{df} 95$, for virgin guinea-pigs aged $150-300 \mathrm{~d}$, and

MEANCS $=0.036$ (percentage body-weight as fat) $+0.390, r 0.513$, df 46 ,

for virgin and reproductive specimens over $400 \mathrm{~d}$ old. These equations are highly significantly different (Student's $t$ test, $t 3 \cdot 37, P<0.001$ ).

\section{Site-specific changes in adipocyte volume}

The mean volumes of adipocytes at each depot are listed in Table 3 (the values given for IFS, IFA, UMN, BA and GS are the means of the separate measurements from homologous depots on the left and right sides of the body). Adipocytes at all depots were larger in fatter animals (see Table 2) than in age-matched groups of thinner specimens, indicating that adipose tissue at all the depots studied acted as an energy store but, as previously reported for guinea-pigs (Pond et al. 1984 a) and for many other mammals (Pond \& Mattacks, 1985a; Pond, 1986), adipocyte volume also depends on the anatomical site from which the samples are derived. Thus the smallest adipocytes (UMN) of young, sedentary ad lib.-fed guinea-pigs (group 2) were almost the same size as the largest adipocytes (GV) from animals of similar age given a restricted diet (groups 6-9), although the former specimens were much fatter (see Table 1).

Site-specific adipocyte volume relative to $M E A N C S$. Changes in the relative volume of adipocytes at different depots are most clearly shown when the site-specific adipocyte volume is expressed relative to the specimen-average adipocyte volume (MEANCS). Age-related decrease in MEANCS was insignificant in guinea-pigs aged less than about $400 \mathrm{~d}$ (see Table 2). Analysis of variance by regimen and sex of the values (see Table 3 ) from all virgin 


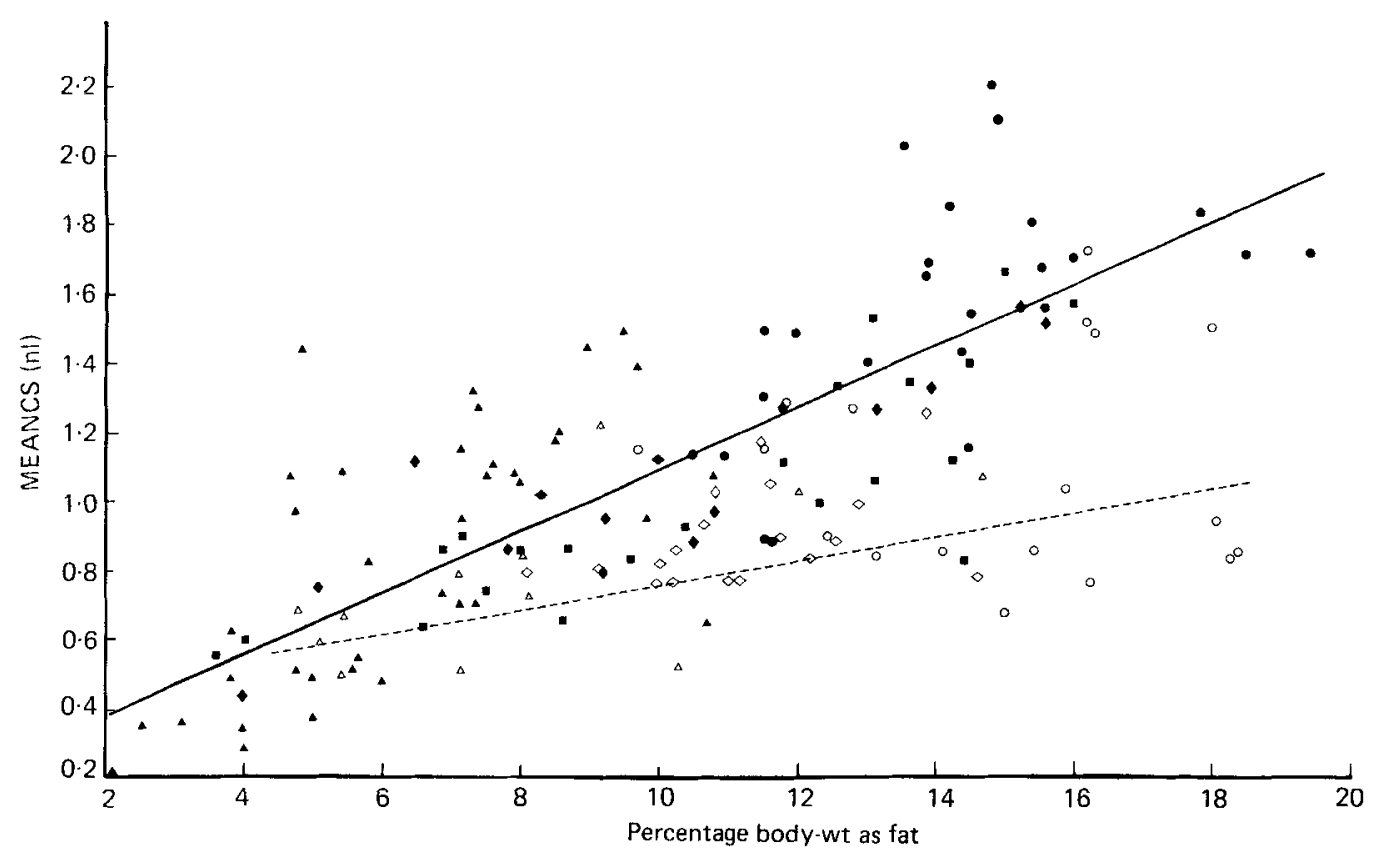

Fig. 1. The relations between mean cell volume (MEANCS; $\mathrm{nl}$ ), based on samples from sixteen anatomical sites, and percentage body-weight as fat, as determined by direct dissection. ---, Virgin and reproductive guinea-pigs over $400 \mathrm{~d}$ old, $n 48 ; 0$, sedentary, ad lib.-fed; $\Delta$, restricted-diet; $\diamond$, strenuously exercised; $\diamond$, formerly exercised. - Virgin guinea-pigs aged 150-300 d, $n 97 ; \boldsymbol{\ominus}$, sedentary ad lib.-fed; $\boldsymbol{\Lambda}$, restricted diet; $\mathbf{0}$, moderately exercised; $\bullet$, strenuously exercised; $\bullet$. restricted exercise.

specimens less than $400 \mathrm{~d}$ old revealed no sex difference in the relative volume of adipocytes at any of the twelve depots. The same analysis showed that the diet and exercise regimens changed the volumes of adipocytes relative to MEANCS highly significantly $(P<0.01)$ in the cases of UMN, GS and POP and significantly $(P<0.05)$ in the cases of IFS, IFA, HUMP, DWA, ATG and GL. Adipocytes at the UMN and HUMP depots became smaller relative to those in other depots in all categories of exercised guinea-pigs (groups 11-14). These effects were partially reversed by the 'formerly exercised' regimen (group 16), and the relative volumes of UMN adipocytes in this group were not significantly different from those of the never-exercised controls (groups 1-3 combined). The relative volume of UMN cells was not altered by the restricted-diet regimen, although their absolute volume decreased by up to $57 \%$ from that of the ad lib.-fed controls of the same age and sex (see Table 3), and became similar to that of the exercised animals, although the exercised females were much fatter.

Adipocytes at the GS depot were relatively smaller in all the restricted-diet animals. The volumes of adipocytes in the middle of POP were relatively smaller in the restricted-diet guinea-pigs (groups 6-9) and larger in the exercised groups (11-14) compared with sedentary, ad lib.-fed controls, particularly in the males. Those at the other intermuscular depot in the hind-limb (GL) were similarly altered by the restricted-diet and exercise regimens. Adipocytes in the two depots anterior to the forelimb (IFS and IFA) became smaller relative to those elsewhere in the body on the exercise regimens, but were unaltered by dietary restriction, while those in the two intra-abdominal depots (DWA and ATG) became relatively smaller only following the regimens that significantly reduced the percentage body-weight as fat (groups 6-9, 11 and 13). 
Table 3. Average volume ( $n l)$ of adipocytes at twelve adipose depots for the fifteen

(Where values from both the left and the right depots were collected, the

\begin{tabular}{|c|c|c|c|c|c|c|c|c|c|c|c|c|}
\hline \multirow{2}{*}{$\begin{array}{l}\text { Group } \\
\text { no.** }\end{array}$} & \multicolumn{2}{|c|}{ DWA } & \multicolumn{2}{|c|}{ ATG } & \multicolumn{2}{|c|}{ BA } & \multicolumn{2}{|c|}{ UMN } & \multicolumn{2}{|c|}{ HUMP } & \multicolumn{2}{|c|}{ GS } \\
\hline & Mean & SD & Mean & SD & Mean & $\mathrm{SD}$ & Mean & SD & Mean & SD & Mean & SD \\
\hline & & & & & & & & & & & \multicolumn{2}{|c|}{ Sedentary, } \\
\hline 1 & 1.989 & 0.255 & 1.672 & 0.215 & 1.583 & 0.485 & $1 \cdot 131$ & $0 \cdot 358$ & 1.318 & 0.299 & 1.863 & 0.220 \\
\hline 2 & 2.003 & 0.415 & 1.963 & 0.227 & 1.613 & 0.399 & 1.175 & $0 \cdot 188$ & 1.519 & 0.317 & 2.008 & 0.326 \\
\hline 3 & 1.651 & 0.837 & $1 \cdot 327$ & 0.541 & 1.345 & 0.453 & 1.016 & 0.352 & $1 \cdot 109$ & 0.410 & 1.674 & 0.368 \\
\hline 4 & 1.399 & 0.430 & $1 \cdot 129$ & 0.384 & 0.999 & $0 \cdot 309$ & 0.711 & 0.299 & 0.977 & 0.360 & 1.412 & 0.336 \\
\hline 5 & $1 \cdot 254$ & 0.436 & $1 \cdot 122$ & 0.337 & 1.056 & $0 \cdot 342$ & 0.749 & $0 \cdot 300$ & 0.858 & 0.334 & 1.414 & 0.368 \\
\hline & & & & & & & & & & & \multicolumn{2}{|c|}{ Sedentary, } \\
\hline 6 & $1 \cdot 032$ & 0.397 & 0.941 & 0.351 & 0.899 & 0.292 & 0.741 & 0.242 & 0.780 & 0.278 & $1 \cdot 172$ & 0.480 \\
\hline 7 & 0.893 & 0.498 & 0.828 & 0.460 & 0.929 & 0.572 & 0.643 & 0.349 & 0.645 & 0.328 & 1.033 & 0.541 \\
\hline 8 & 0.706 & 0.358 & 0.598 & 0.307 & 0.679 & 0.375 & 0.434 & 0.265 & 0.585 & 0.339 & 0.860 & 0.463 \\
\hline 9 & 1.057 & 0.518 & 0.947 & 0.518 & $1 \cdot 191$ & 0.533 & 0.660 & 0.282 & 0.704 & 0.210 & $1 \cdot 264$ & 0.534 \\
\hline 10 & 0.816 & 0.410 & 0.789 & 0.380 & 0.726 & 0.272 & 0.529 & 0.253 & 0.598 & 0.257 & 0.953 & 0.319 \\
\hline & & & & & & & & & & & \multicolumn{2}{|c|}{ Exercised, } \\
\hline 11 & 0.996 & 0.193 & 1.009 & $0 \cdot 300$ & 0.834 & $0 \cdot 209$ & 0.536 & 0.20 & 0.620 & $0 \cdot 168$ & 1.098 & $0 \cdot 158$ \\
\hline 12 & 1.523 & 0.274 & 1.373 & 0.315 & $1 \cdot 191$ & 0.325 & 0.829 & 0.250 & 0.980 & 0.273 & 1.911 & 0.507 \\
\hline 13 & 0.852 & 0.221 & 0.929 & 0.361 & 0.776 & $0 \cdot 204$ & 0.481 & $0 \cdot 149$ & 0.620 & $0 \cdot 190$ & 1.061 & 0.237 \\
\hline 14 & 1.725 & 0.368 & 1.437 & 0.339 & 1.410 & 0.470 & 0.658 & $0 \cdot 104$ & 0.910 & 0.215 & 1.993 & 0.398 \\
\hline 15 & 1.285 & 0.313 & $1 \cdot 189$ & 0.398 & 1.014 & $0 \cdot 176$ & 0.797 & 0.410 & 1.069 & 0.481 & $1 \cdot 508$ & 0.558 \\
\hline 16 & $1 \cdot 172$ & 0.218 & $1 \cdot 246$ & 0.326 & $1 \cdot 091$ & 0.219 & 0.589 & $0 \cdot 117$ & 0.848 & 0.147 & 1.588 & 0.356 \\
\hline 17 & 1.018 & 0.135 & 0.906 & 0.155 & 0.863 & 0.131 & 0.526 & 0.217 & 0.697 & 0.101 & $1 \cdot 168$ & 0.177 \\
\hline
\end{tabular}

- See Table 1 for description of groups and p. 32 for abbreviations of adipose depots.

Analysis of variance was also used to compare the structure of tissues in guinea-pigs over $400 \mathrm{~d}$ old with similarly treated younger specimens of the same sex. The site-specific volume of adipocytes relative to MEANCS was similar for all depots in the males, and for all depots except IFS in the females. In the latter case, the relative volumes of IFS adipocytes were significantly $(P<0.05)$ larger in the mothers (groups 5 and 10$)$ and in the older, strenuously exercised virgins (group 15 ) than in similarly maintained younger females.

Correlation between the volumes of adipocytes. In all seventeen groups, the correlation coefficients between volumes of adipocytes in the four left-right pairs of depots studied (IFS, IFA, UMN, BA) were greater than $0 \cdot 88$, indicating that none of the regimens altered the close coordination between the volume of adipocytes in homologous sites reported by Pond et al. $(1984 a)$.

Following the analysis of Pond et al. $(1984 a)$, the correlation coefficients between the volumes of adipocytes in the twelve depots in ad lib.-fed, sedentary mothers (group 5) were compared with those derived from the values from the age-matched group of males maintained under a similar regimen of diet and exercise (group 4). All the correlations between the volumes of adipocytes in coefficients for the group 4 values were below this value. In all but six cases the correlation coefficients for the values from the older males (group 4) were lower than the corresponding value for the mothers (group 5) and, in four cases, the correlation coefficients between the volumes of adipocytes were significantly higher for the values from group 5 than those from group 4 (Fisher's $z$ transformation test). 
experimental groups of guinea-pigs maintained on different regimens of diet and exercise* means of the two values were used. Mean values and standard deviations)

\begin{tabular}{|c|c|c|c|c|c|c|c|c|c|c|c|}
\hline \multicolumn{2}{|c|}{ GV } & \multicolumn{2}{|c|}{ IFS } & \multicolumn{2}{|c|}{ IFA } & \multicolumn{2}{|c|}{ DC } & \multicolumn{2}{|c|}{ POP } & \multicolumn{2}{|c|}{ GL } \\
\hline Mean & SD & Mean & SD & Mean & SD & Mean & SD & Mean & SD & Mean & SD \\
\hline \multicolumn{12}{|c|}{ ad lib.-fed } \\
\hline $2 \cdot 027$ & $0 \cdot 379$ & 1.256 & 0.205 & $1 \cdot 340$ & 0.548 & $1 \cdot 242$ & 0.220 & $2 \cdot 111$ & 0.484 & 1.804 & 0.347 \\
\hline $2 \cdot 121$ & 0.492 & 1.276 & 0.314 & 1.402 & 0.336 & $1 \cdot 270$ & 0.344 & $2 \cdot 215$ & 0.417 & 1.953 & 0.546 \\
\hline $2 \cdot 049$ & 0.611 & 1.090 & 0.458 & 1.062 & $0 \cdot 366$ & 1.069 & 0.423 & 1.678 & 0.459 & $1 \cdot 521$ & $0 \cdot 398$ \\
\hline 1.734 & $0 \cdot 370$ & 0.858 & 0.259 & 0.707 & 0.255 & 0.822 & 0.281 & $1 \cdot 411$ & 0.561 & 1.285 & 0.570 \\
\hline 1.623 & $0 \cdot 378$ & 0.871 & 0.263 & 0.795 & 0.338 & 0.838 & 0.283 & 1.475 & 0.458 & $1 \cdot 215$ & 0.424 \\
\hline \multicolumn{12}{|c|}{ restricted diet } \\
\hline 1.247 & 0.524 & 0.786 & 0.259 & 0.772 & 0.166 & 0.695 & 0.297 & 0.990 & 0.427 & 0.870 & 0.427 \\
\hline $1 \cdot 230$ & 0.668 & 0.654 & $0 \cdot 389$ & $0 \cdot 716$ & 0.470 & 0.610 & 0.349 & $1 \cdot 114$ & 0.562 & $1 \cdot 017$ & 0.605 \\
\hline 0.945 & 0.450 & 0.583 & 0.401 & 0.556 & 0.375 & 0.460 & 0.314 & 0.765 & 0.320 & 0.810 & 0.466 \\
\hline 1.335 & 0.551 & $0 \cdot 698$ & 0.224 & 0.965 & 0.461 & $0 \cdot 702$ & 0.316 & 1.095 & 0.383 & 1.067 & 0.380 \\
\hline 1.011 & 0.313 & 0.584 & 0.231 & 0.520 & 0.263 & 0.548 & $0 \cdot 268$ & 0.979 & 0.246 & 0.826 & $0 \cdot 300$ \\
\hline \multicolumn{12}{|c|}{ ad lib.-fed } \\
\hline 1.206 & 0.195 & 0.553 & $0 \cdot 159$ & 0.611 & $0 \cdot 151$ & 0.527 & $0 \cdot 138$ & $1 \cdot 135$ & 0.265 & 0.988 & 0.241 \\
\hline 1.996 & 0.342 & 0.956 & 0.245 & 0.955 & $0 \cdot 260$ & 0.934 & 0.265 & 1.779 & 0.437 & 1.441 & 0.252 \\
\hline $1 \cdot 217$ & 0.269 & 0.614 & $0 \cdot 160$ & 0.574 & 0.212 & 0.605 & $0 \cdot 168$ & $1 \cdot 330$ & 0.337 & $1 \cdot 170$ & 0.285 \\
\hline 1.786 & 0.422 & 0.955 & $0 \cdot 185$ & 0.934 & $0 \cdot 240$ & 0.883 & 0.228 & 1.871 & 0.438 & 1.531 & 0.499 \\
\hline $1 \cdot 597$ & 0.389 & 0.866 & $0 \cdot 150$ & 0.848 & $0 \cdot 168$ & 0.767 & 0.201 & 1.339 & 0.255 & 1.176 & 0.325 \\
\hline 1.605 & 0.327 & 0.889 & 0.223 & 0.776 & 0.131 & 0.819 & 0.206 & 1.440 & 0.428 & $1 \cdot 199$ & 0.377 \\
\hline 1.271 & 0.230 & 0.677 & $0 \cdot 119$ & 0.634 & 0.042 & 0.686 & $0 \cdot 128$ & 1.286 & 0.396 & 0.967 & 0.203 \\
\hline
\end{tabular}

\section{Adipose tissue cellularity}

The numbers of adipocytes at eleven depots are listed in Table 4 . The measurements of the total mass of the GL depot (approximately $100 \mathrm{mg}$ ) were not sufficiently accurate to provide a satisfactory basis for the calculation of its cellularity. The large standard deviations in Table 4 indicate that, particularly in the older specimens, there was considerable variation between similarly maintained individuals in the abundance of adipocytes at the depots studied.

Effects of diet and exercise regimen. Analysis of variance of these values showed that, among the virgin guinea-pigs under $400 \mathrm{~d}$ old, there was no sex difference in the cellularity of any depot except GS; adipocytes in this depot were significantly $(P<0.05)$ more numerous in the males on all regimens than in similarly maintained females. Although the total adipocyte complements were smaller in guinea-pigs on the restricted-diet regimen (groups 6-9) than in the ad lib.-fed specimens of the same age (see Table 2), it is clear from Table 4 that the reduction in adipose cellularity was not shared equally between all depots; there were significantly fewer adipocytes in all depots studied except IFA, GV and ATG. Of the two intra-abdominal depots, the cellularity of kidney, channel and gonadal depots (DWA) was depleted to a little over half its normal value by the restricted-diet regimens, while that of the ATG (omental and mesenteric) site was unchanged. The lean body masses of the four groups of virgin guinea-pigs on the restricted-diet regimen (groups 6-9) were significantly lower than those of the ad lib.-fed controls (groups 1-3) (see Table 1), so these thinner animals had more adipocytes, relative to their lean body mass, at depots such as IFA, GV and ATG that were not depleted by the restricted-diet regimen.

Among the younger specimens (groups 11-14), the exercise regimens affected adipose 
Table 4. Cellularity of adipose tissue

(Mean values and

\begin{tabular}{|c|c|c|c|c|c|c|c|c|c|c|}
\hline \multirow{2}{*}{$\begin{array}{c}\text { Group } \\
\text { no.* }\end{array}$} & \multicolumn{2}{|c|}{ DWA } & \multicolumn{2}{|c|}{ ATG } & \multicolumn{2}{|c|}{ BA } & \multicolumn{2}{|c|}{ UMN } & \multicolumn{2}{|c|}{ HUMP } \\
\hline & Mean & SD & Mean & SD & Mean & SD & Mean & SD & Mean & SD \\
\hline & & & & & & & & & Sede & tary, \\
\hline 1 & $23 \cdot 00$ & $4 \cdot 13$ & 22.94 & $5 \cdot 39$ & $8 \cdot 60$ & 3.23 & $9 \cdot 44$ & $5 \cdot 85$ & 15.45 & $3 \cdot 39$ \\
\hline 2 & $19 \cdot 50$ & 4.53 & $19 \cdot 13$ & $4 \cdot 53$ & 6.67 & 0.85 & 7.43 & 1.47 & 11.61 & 2.84 \\
\hline 3 & 22.71 & $8 \cdot 03$ & 26.66 & $8 \cdot 52$ & $7 \cdot 81$ & 3.04 & $9 \cdot 66$ & $6 \cdot 13$ & 15.77 & 5.65 \\
\hline 4 & 39.83 & $20 \cdot 13$ & $39 \cdot 24$ & $15 \cdot 32$ & 13.99 & 6.79 & 14.79 & 11.62 & $26 \cdot 32$ & 13.43 \\
\hline \multirow[t]{2}{*}{5} & $43 \cdot 84$ & $15 \cdot 98$ & 38.45 & 16.94 & $14 \cdot 19$ & $4 \cdot 35$ & $9 \cdot 83$ & 4.52 & $21 \cdot 96$ & 11.90 \\
\hline & & & & & & & & & \multicolumn{2}{|c|}{ Sedentary, } \\
\hline 6 & 13.48 & $5 \cdot 30$ & $19 \cdot 52$ & 11.98 & $5 \cdot 19$ & $2 \cdot 39$ & $3 \cdot 90$ & $4 \cdot 34$ & $11 \cdot 13$ & $5 \cdot 10$ \\
\hline 7 & $14 \cdot 35$ & 4.55 & 20.97 & 7.59 & $5 \cdot 35$ & 2.59 & 3.60 & $2 \cdot 00$ & 10.78 & 5.03 \\
\hline 8 & $15 \cdot 17$ & 5.03 & $23 \cdot 14$ & 11.80 & 6.51 & $2 \cdot 07$ & 5.99 & $4 \cdot 12$ & 10.96 & $3 \cdot 12$ \\
\hline 9 & $15 \cdot 71$ & $5 \cdot 52$ & $19 \cdot 15$ & 8.37 & 4.51 & 1.49 & $7 \cdot 12$ & $2 \cdot 83$ & 11.51 & 2.88 \\
\hline \multirow[t]{2}{*}{10} & $28 \cdot 39$ & $15 \cdot 18$ & 25.90 & $9 \cdot 21$ & 9.87 & 5.91 & $5 \cdot 50$ & 1.99 & $14 \cdot 46$ & 10.63 \\
\hline & & & & & & & & & \multicolumn{2}{|c|}{ Exercised, } \\
\hline 11 & $22 \cdot 31$ & 8.59 & $22 \cdot 29$ & $7 \cdot 11$ & $7 \cdot 33$ & 2.55 & $8 \cdot 55$ & $4 \cdot 61$ & $15 \cdot 21$ & $4 \cdot 42$ \\
\hline 12 & 21.67 & $5 \cdot 20$ & $22 \cdot 55$ & $7 \cdot 17$ & $8 \cdot 14$ & $2 \cdot 35$ & 10.46 & $5 \cdot 24$ & 16.71 & 5.82 \\
\hline 13 & $27 \cdot 10$ & 7.97 & $24 \cdot 71$ & 8.98 & 9.04 & 2.83 & $9 \cdot 14$ & 6.25 & 18.28 & 9.06 \\
\hline 14 & $20 \cdot 17$ & 12.96 & 22.02 & $10 \cdot 47$ & $7 \cdot 70$ & $5 \cdot 46$ & $11 \cdot 30$ & 2.65 & $17 \cdot 14$ & $7 \cdot 14$ \\
\hline 15 & $24 \cdot 38$ & 9.26 & $23 \cdot 51$ & 8.33 & $9 \cdot 12$ & $4 \cdot 28$ & 10.02 & $4 \cdot 48$ & 16.99 & 4.05 \\
\hline 16 & 25.89 & $7 \cdot 26$ & $26 \cdot 74$ & 11.81 & 8.52 & $2 \cdot 45$ & $10 \cdot 24$ & $11 \cdot 37$ & $18 \cdot 31$ & 6.05 \\
\hline 17 & $34 \cdot 75$ & 6.58 & 37.96 & $7 \cdot 04$ & 10.98 & 2.75 & 14.04 & $6 \cdot 81$ & $20 \cdot 47$ & 5.84 \\
\hline
\end{tabular}

* See Table 1 for description of groups and p. 32 for abbreviations of adipose depots.

tissue cellularity only in the HUMP and UMN depots where, in the females only, the numbers of adipocytes in both depots were significantly greater than in the sedentary, ad lib.-fed controls. A similar change in the structure of the UMN and HUMP adipose depots would be more difficult to detect in the males, because on both exercise regimens they became much thinner than the sedentary controls (see Table 1), and the abundance of UMN and HUMP adipocytes was variable in all groups of sedentary and exercised males. There was no significant difference in the abundance of adipocytes in any depot in the younger, formerly exercised animals (group 16), compared with the never-exercised ones (groups 1-3).

The effects of age. There was no significant difference between the males aged about 7 months (group 1) and those aged about 10 months (group 3) in the numbers of adipocytes at any of the depots studied. However, the cellularities of all depots except UMN, GV and DC were significantly greater $(P<0.01)$ in male guinea-pigs over $400 \mathrm{~d}$ old than in the younger specimens. All depots except UMN, HUMP and DC contained more adipocytes in the sedentary groups of older mothers (groups 5 and 10) than in the similarly maintained younger virgin females. Age-related accumulation of adipocytes was curtailed in all depots studied in the older, strenuously exercised virgin females (group 15). The comparison between the younger, formerly exercised specimens (group 16) and the similarly treated older animals (group 17) revealed a trend towards greater cellularity in all depots studied, but the effect was significant only in the cases of the two intra-abdominal depots. There were $34 \%$ more adipocytes in the DWA depot and $42 \%$ more in the ATG site, and $42 \%$ more in the older restricted-exercise specimens (group 17) than in the group 16 animals.

The total adipocyte complement of the older, formerly exercised animals (group 17) was not significantly smaller than that of the never-exercised males and mothers (groups 4 and 5), but the various depots did not contribute equally to the greater adipocyte complement. 
( $\times 10^{6}$ adipocytes) at eleven adipose depots*

standard deviations)

\begin{tabular}{|c|c|c|c|c|c|c|c|c|c|c|c|}
\hline \multicolumn{2}{|c|}{ GS } & \multicolumn{2}{|c|}{ GV } & \multicolumn{2}{|c|}{ IFS } & \multicolumn{2}{|c|}{ IFA } & \multicolumn{2}{|c|}{ DC } & \multicolumn{2}{|c|}{ POP } \\
\hline Mean & $\mathrm{SD}$ & Mean & SD & Mean & SD & Mean & SD & Mean & $\mathrm{SD}$ & Mean & SD \\
\hline \multicolumn{12}{|c|}{$a d$ lib.-fed } \\
\hline 7.73 & $2 \cdot 54$ & $4 \cdot 87$ & $1 \cdot 90$ & $4 \cdot 18$ & $1 \cdot 21$ & 3.92 & 4.49 & $5 \cdot 37$ & 1.55 & 1.58 & 0.39 \\
\hline $5 \cdot 22$ & 1.08 & $3 \cdot 88$ & 1.45 & $4 \cdot 31$ & $2 \cdot 14$ & $2 \cdot 73$ & 1.03 & 4.82 & 2.08 & 1.42 & 0.23 \\
\hline 8.73 & 3.05 & $4 \cdot 50$ & $2 \cdot 34$ & $2 \cdot 64$ & $2 \cdot 27$ & $3 \cdot 28$ & $2 \cdot 03$ & 5.60 & $2 \cdot 43$ & 1.80 & 0.25 \\
\hline $12 \cdot 07$ & $6 \cdot 10$ & $6 \cdot 21$ & 3.49 & $7 \cdot 32$ & $5 \cdot 44$ & $9 \cdot 56$ & $7 \cdot 36$ & $7 \cdot 40$ & 3.56 & $2 \cdot 22$ & 0.75 \\
\hline $10 \cdot 63$ & 3.62 & $5 \cdot 89$ & 4.02 & $6 \cdot 42$ & 3.88 & 8.94 & $10 \cdot 23$ & 6.36 & $2 \cdot 27$ & $2 \cdot 13$ & 0.94 \\
\hline \multicolumn{12}{|c|}{ restricted diet } \\
\hline $5 \cdot 32$ & $2 \cdot 71$ & $3 \cdot 35$ & $2 \cdot 27$ & $2 \cdot 38$ & 2.09 & 1.78 & 1.09 & $3 \cdot 13$ & $2 \cdot 80$ & $1 \cdot 04$ & 0.60 \\
\hline $4 \cdot 29$ & $1 \cdot 34$ & $2 \cdot 46$ & $1 \cdot 12$ & 1.99 & 1.49 & $4 \cdot 14$ & 4.95 & $3 \cdot 27$ & $2 \cdot 15$ & 1.03 & $0 \cdot 35$ \\
\hline 6.41 & $2 \cdot 80$ & $3 \cdot 96$ & $2 \cdot 57$ & $2 \cdot 22$ & 2.69 & $4 \cdot 46$ & $3 \cdot 30$ & $4 \cdot 20$ & $2 \cdot 35$ & 1.03 & 0.29 \\
\hline $3 \cdot 53$ & 1.41 & $3 \cdot 66$ & $1 \cdot 39$ & 0.91 & 0.46 & $2 \cdot 40$ & $2 \cdot 16$ & $5 \cdot 18$ & 1.78 & $1 \cdot 08$ & $0 \cdot 17$ \\
\hline 7.09 & $4 \cdot 56$ & $4 \cdot 36$ & 3.08 & $4 \cdot 20$ & $2 \cdot 18$ & 6.32 & $5 \cdot 29$ & 5.80 & 2.87 & $1 \cdot 32$ & 0.60 \\
\hline \multicolumn{12}{|c|}{ ad lib.-fed } \\
\hline 7.67 & $3 \cdot 20$ & 4.8 & 3.07 & $3 \cdot 4$ & $2 \cdot 34$ & $3 \cdot 19$ & 1.79 & $4 \cdot 84$ & $3 \cdot 34$ & 1.53 & 0.60 \\
\hline $5 \cdot 36$ & 1.43 & 3.90 & $1 \cdot 33$ & $5 \cdot 21$ & 2.96 & $3 \cdot 28$ & $1 \cdot 11$ & 7.63 & $3 \cdot 12$ & 1.49 & 0.51 \\
\hline $9 \cdot 32$ & $2 \cdot 86$ & $4 \cdot 23$ & $2 \cdot 28$ & $3 \cdot 27$ & $2 \cdot 41$ & $5 \cdot 31$ & $4 \cdot 90$ & 4.07 & $2 \cdot 83$ & 1.44 & $0 \cdot 44$ \\
\hline 5.69 & $2 \cdot 58$ & 4.84 & 1.95 & $3 \cdot 14$ & $3 \cdot 48$ & 4.59 & $5 \cdot 27$ & $6 \cdot 12$ & $2 \cdot 14$ & 1.33 & 0.42 \\
\hline 6.96 & $3 \cdot 38$ & $4 \cdot 61$ & $2 \cdot 60$ & $3 \cdot 23$ & $2 \cdot 48$ & $3 \cdot 49$ & 1.72 & $5 \cdot 32$ & $2 \cdot 88$ & 1.76 & 0.39 \\
\hline $7 \cdot 38$ & $2 \cdot 80$ & $4 \cdot 02$ & 1.64 & $4 \cdot 64$ & 0.81 & 4.93 & $1 \cdot 27$ & $4 \cdot 80$ & $2 \cdot 24$ & 1.86 & 0.63 \\
\hline $9 \cdot 88$ & 2.75 & $5 \cdot 38$ & 2.94 & $5 \cdot 48$ & $2 \cdot 63$ & 6.05 & 3.04 & 5.87 & 1.95 & 1.85 & 0.80 \\
\hline
\end{tabular}

At one very large depot (ATG) there were less than $5 \%$ fewer adipocytes in the formerly exercised specimens, and the differences between group 17 and groups 4 and 5 combined were less than $20 \%$ in the cases of the UMN, GS, GV, HUMP, DC, DWA and POP sites. However, there were over $30 \%$ fewer adipocytes in the three smaller depots around the forelimb (BA, IFA and IFS) in the guinea-pigs that had exercised strenuously for 3 months of their lives than in never-exercised specimens of the same age. At similar percentage body-weight as fat, the exercised animals would have relatively lean shoulders and forelimbs but more massive abdominal depots, while the adipose tissue would be more evenly distributed on the bodies of those that were sedentary throughout life.

The depots that were most depleted by the restricted-diet regimens did not correspond exactly to those that showed the most age-related proliferation of adipocytes. The cellularities of the IFA, GV and ATG depots were not significantly reduced by the restricted-diet regimen, but those of IFA and ATG increased substantially in the unexercised older specimens; on the other hand, the UMN depot, although much depleted in the sedentary, restricted-diet guinea-pigs, did not show significant age-related accumulation of adipocytes. Of the depots examined, DWA proved to be the most affected, and DC the least affected, by age and diet and exercise regimens.

\section{DISCUSSION \\ Methods}

Roche (1981) reviewed various widely used techniques for determining MEANCS and concluded that measurement of maximum adipocyte diameter from whole mounts, although tedious and time-consuming, was a 'very satisfactory method'. We have used it successfully 
for sizing adipocytes ranging in volume from $50 \mathrm{pl}$ to $4 \mathrm{nl}$ in tissue samples from a wide variety of wild and captive mammals and birds (Pond \& Mattacks, 1985b,c). In the present study and in a previous investigation using the same methods (Pond et al. 1984a), we found that the correlation between the independent determinations of the MEANCS in left-right pairs of depots was consistently high, indicating that the method yields reproducible results. The values we obtained for adipocyte volume were very similar to those reported by Kirtland et al. (1976).

\section{Age effects}

The results from groups 4,5 and 17 show that cells clearly recognizable as mature adipocytes became more numerous but smaller in older guinea-pigs, if they were fed ad lib. and did not exercise regularly. This phenomenon has been described in the storage of adipose tissue at certain intra-abdominal and groin depots in unexercised, normal (Lemmonier, 1972; Stiles et al. 1975; Bertrand et al. 1978; DeMartinis \& Francendese 1982) and genetically obese (Johnson \& Hirsch, 1972; Johnson et al. 1978) rats and mice, and in the metabolically inert, structural adipocytes inside the eyesocket of guinea-pigs (Mattacks \& Pond, 1985). The results presented here extend the previous observations in three ways.

First, the values from the guinea-pigs aged about 16 months which were first exercised strenuously and then confined in smaller pens (group 17) showed that the age-related accumulation of adipocytes was not necessarily accompanied by adipocyte enlargement, nor was it preceded by a period of high percentage body-weight as fat. The age-related changes in adipose tissue structure did not inevitably cause the specimens to become fatter, because adipocytes at all depots studied except UMN became smaller as they became more abundant (groups 1 and 3 compared with group 4, and groups 13 and 14 compared with group 16). It is not possible to determine from our findings whether the appearance of additional adipocytes was due to proliferation de novo of additional cells or to the maturation of pre-adipocytes that were already in existence. However, these results are not consistent with the scheme proposed by Björntorp et al. (1982), suggesting that the appearance of additional mature adipocytes in adult animals occurs when the existing population becomes 'full up'. DeMartinis \& Francendese (1982) measured the diameters of 300 adipocytes from the epididymal depots of rats aged 6-120 weeks. Although the authors chose not to emphasize the observation, it is clear from their Fig. 2 that the mean diameter of the 'large fat cell' population became significantly smaller in the oldest rats but, nonetheless, the abundance and mean diameter of the 'very small fat cell' population were almost identical to those measured from rats aged less than $100 \mathrm{~d}$. They found no evidence for age-related depletion of the numbers of 'very small fat cells' or that the two populations merged. Therefore, while any population of very small fat cells may not have been detected by our methods, their occurrence may be irrelevant to the age-related changes in the structure of the 'large fat cell' population.

An inverse relation between adipocyte abundance and adipocyte volume has been noticed in comparative studies of mammalian and avian adipose tissue (Pond \& Mattacks, $1985 b, c)$ and in rat adipocytes grown in tissue culture on collagen-coated coverslips (Hausman et al. 1985). This effect may also explain the findings of Reyne et al. (1985) from serial biopsies of the kidney (DWA) and dorsoscapular (HUMP) depots of ad lib.-fed New Zealand white rabbits kept in 'small cages' from birth to the age of 11 months. They observed brief periods during which the mean adipocyte diameter decreased, and the standard deviation of the diameter increased; the mean diameter of the HUMP adipocytes also gradually declined after the age of $150 \mathrm{~d}$, although there was no evidence that the rabbits were becoming thinner.

Second, age-related changes in adipose tissue structure were not observed in the older, 
strenuously exercised females (group 15), suggesting that regular exercise may help postpone adipocyte accumulation. Under all conditions investigated, adipocytes became smaller as they became more numerous at constant percentage body-weight as fat, so if adipocyte volume is used as the only measure of fatness, specimens that exercise continually may appear to be as fat or fatter than sedentary controls of the same age. Such effects may underlie the disappointingly small differences in the volumes of superficial adipocytes of human athletes and sedentary people (Tremblay et al. 1984). Only 6 weeks on the restricted-exercise regimen (group 17) were sufficient for the appearance of as many adipocytes as were observed in the never-exercised specimens of the same age (groups 4 and 5). The observations of Reyne et al. (1985) suggest that in young rabbits, additional adipocytes can mature and the storage lipid can be redistributed between them and the existing population in less than 2 weeks.

Third, the findings showed that, over the period of the life-history investigated, age-related adipocyte accumulation did not occur to the same extent in all depots, being greatest in the intra-abdominal depots and those around the forelimb, and least in the groin and UMN depots. There was no age-related change in relative adipocyte volume (see Table 4) (except the GV site of males) that would counteract the effects of differential adipocyte accumulation to maintain a constant relative mass of tissue. Consequently, depots such as those around the forelimb and the intra-abdominal sites would become relatively more massive in older specimens as mature adipocytes accumulate in them, causing a gradual change in body conformation with advancing age.

There is a substantial increase in the total cellularity of adipose tissue in guinea-pigs older than about 1 year, or after about $15 \%$ of the maximum life-span of about 7 years (Comfort, 1979) has elapsed, although older specimens are not necessarily fatter (see Table 1). Age-related accumulation of adipocytes may explain our observation (Pond \& Mattacks, $1985 \mathrm{~b}$ ) that the numbers of adipocytes per kg body mass of many of the largest specimens of certain wild mammals, notably badgers (Meles meles), were greater than that of the smaller specimens of the same species, although the latter were not necessarily thinner. As expected from previous studies (Pond et al. 1984a), the relation between MEANCS and percentage body-weight as fat (Fig. 1) was more variable in fatter specimens. The very large adipocytes, thought to be a special property of guinea-pigs (Kirtland \& Gurr, 1979), were found only in young adults. Adipocyte volume is a satisfactory indicator of percentage body-weight as fat only in young adults, for which a tenfold increase in fatness corresponds to a fivefold increase in adipocyte volume; in the older specimens, adipocyte accumulation plays such a significant part in determining fatness that adipocyte volume is not a reliable indicator of percentage body-weight as fat even when samples from several depots are examined.

Lactation, like starvation and strenuous exercise, promotes depletion of energy reserves, particularly in small mammals (Vernon \& Flint, 1984); the results from groups 10 and 16 show that frequent maternity combined with dietary restriction or regular, strenuous exercise can delay the age-related accumulation of adipocytes but, as the results from groups 5 and 17 show, both adipose tissue cellularity and the mean adipocyte volume quickly increase if exercise and breeding end and the ad lib. diet is maintained. The comparisons between sedentary mothers, exercised virgins and sedentary males of the same age (groups 4,5 and 15) failed to reveal any long-term change in the structure or distribution of adipose tissue that could be attributed to maternity per se. In spite of the high percentage body-weight as fat and the large total adipocyte complement of the ad lib-fed mothers (group 5), the correlations between the volumes of adipocytes at most of the depots in the mothers were similar to those found by Pond et al. (1984a) in young virgin guinea-pigs maintained on the moderately exercised and restricted-diet regimens. These findings are consistent with 
the suggestion that adipocytes from all the depots studied participate in the storage and release of lipids during lactation, and that regular maternity, like exercise and dietary restriction, promotes greater inter-depot coordination in the enlargement and depletion of adipocytes.

\section{Effects of dietary restriction and exercise on body composition}

The responses of both sexes to the restricted-diet regimen were similar, but there was a clear-cut sex difference in the response to the exercise regimens: the males became thinner on both exercise regimens (groups 11 and 13), but similarly treated females (groups 12, 14 and 15 ) remained as fat, with equally large adipocytes, as the never-exercised controls. The similarity between the numbers of adipocytes per $\mathrm{kg}$ lean body mass in groups $6-9$ and groups 1-3 suggests that the restricted-diet regimen depletes the number of mature, visible adipocytes to about the same extent as it causes the breakdown of lean tissue. Exercise alone did not affect the normal adipocyte complement, even though the males became almost as thin on this regimen as they did following dietary restriction.

\section{Site-specific effects on adipocyte volume}

Adipocytes at all depots studied became smaller when the percentage body-weight as fat decreased, whether the decrease was caused by dietary restriction (groups 6-10), or by exercise (groups 11 and 13). Adipocytes at the depots in which adipose tissue cellularity increased significantly with age were also smaller in the older specimens (groups 4 and 5). There were some small differences in site-specific volumes of the adipocytes relative to those in other depots. The largest and most consistent change was in the UMN adipocytes, which became relatively smaller following exercise, and relatively larger in the restricted-diet, sedentary controls. The effect was similar in both sexes, in spite of the fact that, under both exercise regimens, the females remained much fatter than the males and had larger adipocytes in all depots studied (see Tables 1 and 3). The increase in the relative volume of the adipocytes in the middle of the POP depot in the exercised guinea-pigs, and the reduction in its relative volume in sedentary specimens on the restricted diet, are consistent with the suggestion put forward by Pond et al. (1984b) that the mechanical activity of adjacent muscles can modify the volume of adipocytes in intermuscular depots. However, the effects were sufficiently small that they would contribute little to age-related or regimen-related changes in body conformation and, except in the cases of the UMN and POP depots, none of these regimens offers a promising means of investigating the factors that maintain site-specific differences in adipocyte volume, about which very little is known (Pond, 1986).

\section{Site-specific effects on adipose tissue cellularity}

The fact that age-related accumulation of adipocytes did not occur at the same rate in all depots suggests that the various depots are formed from lineages of cells which differ both in their growth characteristics and in their physiological properties.

The exercised males (groups 11 and 13) became almost as thin as the restricted-diet specimens, but these regimens did not modify the development of the normal adipocyte complement at any of the depots studied. Normal adipocyte complements also developed at all depots except UMN in the females. In the females only, adipocytes at the UMN and HUMP depots became significantly more numerous under both exercise regimens. This observation, and the fact that adipocytes at this depot were the only ones to become relatively smaller following exercise, suggest that adipocytes at these depots play some special role in exercise. Although the guinea-pigs in the outdoor pen were exposed to cooler night-time temperatures than those kept indoors, we do not believe that the observed changes in adipose tissue structure were a direct result of environmental temperature 
because the total time outside was similar in both the moderately exercised (groups 11 and 12) and the strenuously exercised (groups 13,14 and 15) animals; the effect was partially reversed in the formerly exercised specimens (groups 16 and 17) although they spent a longer period outside than the continuously exercised specimens.

The UMN and HUMP depots resemble typical white adipose tissue in that the adipocytes are much larger than those of brown adipose tissue (Suter, 1969) and expand and shrink with changes in overall fatness, but their unusual properties may have some connection with the fact that brown adipose tissue is found at these depots in neonatal mammals of many species, including guinea-pigs (Rowlatt et al. 1971).

The adipocyte complements of several depots, particularly DWA, were significantly lower in specimens on the restricted-diet regimens than in ad lib.-fed controls of similar age, while those of the other intra-abdominal depot (ATG), and two superficial depots (IFA and GV) were similar to those of the controls. The depots that showed the greatest reduction in adipose tissue cellularity under the restricted-diet regimen did not correspond exactly to those that showed the greatest age-related increases in adipocyte number (groups 4 and 5). There were fewer UMN adipocytes in most of the restricted-diet specimens than in age-matched ad lib.-fed specimens of the same sex but, as with the response to the exercise regimens, the effects on this depot were more extensive and more consistent in the females than in the males. Adipocytes at the HUMP depot were significantly less numerous only in the males, although the restricted-diet females became as thin as the similarly treated males.

The responses of the ATG, GV and IFA depots are thus consistent with the widely accepted model, based on the study of the epididymal fat pad of young adult rats (Hirsch \& Han, 1969), that adipose tissue cellularity cannot be reduced by dietary restriction. There are three possible explanations for the effects of dietary restriction on the cellularity of the other depots: (1) the full complement of adipocytes in the unaffected depots develops early in ontogeny and is already complete by the time the treatments begin, at which time adipocyte formation at the other depots is still in progress and can be arrested by the regimen; (2) age-related accumulation of adipocytes normally occurs at all depots, but the restricted-diet regimen effectively curtails the process only in certain depots; (3) partly or completely formed adipocytes are eliminated from certain depots following dietary restriction, but are retained in other depots.

That fact that the effects of the restricted-diet regimen were similar in the older specimens (groups 8 and 9) and in the younger ones (groups 6 and 7) makes suggestions 1 and 2 improbable: these older specimens were the same age as those of groups 1 and 2 when the restricted-diet regimen was imposed, and the comparison between group 1 and group 3 shows clearly that the complement of adipocytes normal for young adults has already developed by the age of 6 months. We suggest, therefore, that in certain depots, adipocytes disappear or become too small to be detectable following dietary restriction, possibly entering the 'very small fat cell' population (DeMartinis \& Francendese, 1982), and that the overall rate at which the process takes place is similar to the rate of loss of lean body mass. The effect was particularly marked in the DWA (kidney) depot, the same site in which diet-induced increases in adipose tissue cellularity have been reported in young rats (Bertrand et al. 1978; Faust et al. 1978).

Adipocytes in those depots that appear to be less numerous under dietary restriction do not become relatively larger under the restricted-diet regimen (see Table 4). Therefore, this regimen alters body conformation as the total mass of adipose tissue becomes relatively larger at certain depots, but the diet-induced modifications to adipose tissue distribution are different from those caused by age-related effects. 


\section{Comparisons with humans}

The sex difference in the effects of regular exercise on body composition is similar in humans and guinea-pigs. The body masses of the five obese young men studied by Tremblay et al. (1984) were reduced by an average of nearly $40 \mathrm{~kg}$, and their supra-iliac adipocytes became as small as $0.1 \mathrm{nl}$. However, the rigorous exercise regimen imposed on ten obese women by Krotkiewski et al. (1984) did not cause significant reduction in their percentage body-weight as fat.

The fact that the older guinea-pigs (group 10) lost as much weight and became as thin as the younger specimens which had fewer adipocytes is consistent with the conclusions of Strain et al. (1984) that adipose tissue cellularity does not affect the success of weight reduction by dieting in people aged $20-55$ years. However, the limited information available suggests that age-related accumulation of adipocytes in humans could only be a minor factor in explaining the discrepancy between the human adipocyte complement predicted from comparative data (Pond \& Mattacks, 1985b) and estimates from living subjects (Hirsch \& Batchelor, 1976; Sjöström \& Björntorp, 1974). Sjöström \& Björntorp (1974) measured the mean volume of adipocytes from three superficial sites of 137 people and, although they found the largest adipocytes in people aged 30-40 years, they concluded that in non-obese subjects the number of adipocytes increases by only about $10 \%$ during adult life.

Unfortunately, the anatomy of human adipose tissue has not yet been studied from the comparative point of view, and the exact homologies between human adipose depots and those in guinea-pigs and other mammals remain unknown. However, the responses of the different depots to the regimens suggest some mechanisms that may be involved in the formation of human body shapes. The time-course of human post-natal growth is very different from that of almost all mammals that have been studied; the rate of growth slows during childhood and accelerates during adolescence (Tanner, 1978). The subscapular and triceps skinfolds are smaller in boys than girls from the age of 2 years (Tanner \& Whitehouse, 1975). Obesity in middle-aged men is characterized by enlargement of the omental and mesenteric depots (ATG) and the superficial abdominal depot (GV) (forming the 'paunch') (Sjöström \& Björntorp, 1974; Björntorp et al. 1975; Lanska et al. 1985) and by the development of more massive depots around the shoulders and upper arm (approximately equivalent to the IFS and IFA depots), while other depots, notably those on the legs (possibly homologous with GS and POP), enlarge only slightly. The development of these figure types could be explained if leanness during childhood curtails adipocyte accumulation in most depots except ATG, GV and IFA, giving rise to more adipocytes, in relation to fatness and body mass, at these depots. Strenuous exercise during youth, followed by a more sedentary middle age, is comparable to the 'formerly exercised' regimen which, in guinea-pigs, is associated with relatively fewer adipocytes around the shoulders and forelimbs; if this life-style has similar effects on human adipocyte proliferation, it would further promote the spindly limbs but rotund abdomens, typical of moderate obesity in middle-aged men.

In contrast, obesity in middle-aged women typically involves much more uniform expansion of many superficial and intra-abdominal depots; such figures would be expected if, because they remained fatter during childhood and perform less regular and less strenuous exercise during early adulthood, adipocyte accumulation followed a time-course similar to that of the ad lib.-fed sedentary guinea-pigs. We also found that older guinea-pigs had proportionately more adipocytes in the intra-abdominal depots and that they did not become smaller relative to those elsewhere in the body except following dietary restriction. The consequences of this process for body shape are consistent with the conclusions reached by Lanska et al. (1985) from their survey of nearly 53000 American women. They found 
that the ratio, waist: hip circumference, increased with increasing age, presumably caused by more massive intra-abdominal adipose tissue, but, as in guinea-pigs, very little of the variation in adipose tissue distribution could be attributed to parity and previous history of obesity.

\section{Conclusions}

Adipocytes at all depots studied were more abundant in older animals; unless the percentage body-weight as fat increased, adipocytes became smaller as they became more numerous. MEANCS was a satisfactory indicator of percentage body-weight as fat only in young adult guinea-pigs in which adipose tissue cellularity was not changing.

In adult guinea-pigs placed on a restricted-diet regimen, the total number of detectable adipocytes decreased approximately in proportion to the decrease in lean body mass, but the depots studied were not depleted equally. Consequently, the cellularity of certain adipose depots can be greater in proportion to lean body mass and total adipocyte complement following dietary restriction than in ad lib.-fed specimens.

The response of the two depots of small adipocytes under the trapezius muscle of the neck and between the scapulas to increased exercise differed from that of adipocytes in the other depots studied.

Differences in the numbers of adipocytes at each depot made a greater contribution to inter-individual differences in the distribution of adipose tissue than the relative volume of adipocytes at each depot. Therefore, a thorough study of the factors that determine the site-specific differences in the rates of accumulation of functional adipocytes would contribute more to an explanation for the distribution of adipose tissue on the body than further studies on the control of adipocyte volume.

The authors thank the Open University Research Committee for a project grant for consumables and financial support for M.C.T.

\section{REFERENCES}

Bertrand, H. A., Masoro, E. J. \& Yu, B. P. (1978). Science 201, 1234-1235.

Björntorp, P., Calgren, G., Isaksson, B., Krotkiewski, M., Larsson, B. \& Sjöström, L. (1975). American Journal of Clinical Nutrition 28, 445-452.

Björntorp, P., Karlsson, M. \& Petterson, P. (1982). Metabolism: Clinical and Experimental 31, 366-373.

Comfort, A. (1979). The Biology of Senescence. Edinburgh: Churchill Livingstone.

Cryer, A. \& Jones, H. M. (1978). Biochemical Journal 172, 319-325.

DeMartinis, F. D. \& Francendese, A. (1982). Journal of Lipid Research 23, 1107-1120.

Di Girolamo, M., Medlinger S. \& Fertig, J. W. (1971). American Journal of Physiology 221, 850-858.

Faust, I. M., Johnson, P. R., Stern, J. S. \& Hirsch, J. (1978). American Journal of Physiology 235, E279-E286.

Fried, S. K., Lavau, M. \& Pi-Sunyer, F. X. (1982). Metabolism: Clinical and Experimental 31, 876-883.

Goldrick, R. B. (1967). American Journal of Physiology 212, 777-782.

Hausman, G. J., Novakofski, J. E., Ramsay, T. \& Martin, R. J. (1985). Journal of Animal Science 60, 1553-1561.

Hirsch, J. \& Batchelor, B. (1976). Clinics in Endocrinology and Metabolism 5, 299-311.

Hirsch, J. \& Han, P. W. (1969). Journal of Lipid Research 10, 77-82.

Johnson, P. R. \& Hirsch, J. (1972). Journal of Lipid Research 13, 2-11.

Johnson, P. R., Stern, J. S., Greenwood, M. R. C. \& Hirsch, J. (1978). Metabolism: Clinical and Experimental 27, 1941-1954.

Kirtland, J. \& Gurr, M. I. (1979). International Journal of Obesity 3, 15-55.

Kirtland, J., Gurr, M. I. \& Widdowson, E. M. (1976). Nutrition and Metabolism 20, 338-350.

Krotkiewski, M., Björntorp, P., Holm, G., Marks, V., Morgan, L., Smith, U. \& Feurle, G. E. (1984). International Journal of Obesity 8, 193-199.

Lanska, D. J., Lanska, M. J., Hartz, A. J. \& Rimm, A. A. (1985). International Journal of Obesity 9, $29-38$.

Lemmonier, D. (1972). Journal of Clinical Investigation 51, 2907-2915.

Mattacks, C. A. \& Pond, C. M. (1985). British Journal of Nutrition 53, 207-213.

Nie, N. H., Hull, C. H., Jenkins, J. G., Steinbrenner, K. \& Brent, D. H. (1975). Statistical Package for the Social Sciences, 2nd ed. New York: McGraw-Hill. 
Pond, C. M. (1986). Science Progress 70, 45-71.

Pond, C. M. \& Mattacks, C. A. (1985a). In Functional Morphology of Vertebrates, [H.-R. Duncker and G. Fleischer, editors]. Stuttgart and New York: Gustav Fischer Verlag.

Pond, C. M. \& Mattacks, C. A. (1985b). Journal of Morphology 185, 183-193.

Pond, C. M. \& Mattacks, C. A. (1985c). Journal of Morphology 185, 194-202.

Pond, C. M., Mattacks, C. A. \& Sadler, D. (1984a). British Journal of Nutrition 51, 415-424.

Pond, C. M., Mattacks, C. A. \& Sadler, D. (1984b). British Journal of Nutrition 51, 425433.

Reyne, Y., Teyssier, J., Nougues, J. \& Tebibel, S. (1985). Journal of Lipid Research 26, 1036-1046.

Roche, A. F. (1981). Child Development 52, 31-43.

Rowlatt, U., Mrosovsky, N. \& English, A. (1971). Biology of the Neonate 17, 53-83.

Sjöström, L. \& Björntorp, P. (1974). Acta Medica Scandinavica 195, 201-211.

Stiles, J. W., Francendese, A. \& Masoro, E. J. (1975). American Journal of Physiology 229, 1561-1568.

Strain, G. W., Strain, J. J., Zumoff, B. \& Knittle, J. (1984). International Journal of Obesity 8, 53-59.

Suter, E. R. (1969). Journal of Ultrastructural Research 26, 216-241.

Tanner, J. M. (1978). Foetus into Man: Physical Growth from Conception to Maturity. London: Open Books.

Tanner, J. M. \& Whitehouse, R. H. (1975). Archives of Diseases of Childhood 50, 142-145.

Tremblay, A., Despres, J. P. \& Bouchard, P. (1984). International Journal of Obesity 8, 641-648.

Vernon, R. G. \& Flint, D. J. (1984). Symposium of the Zoological Society of London 51, 119-145. 